Classification

Physics Abstracts

$61.16-61.46$

\title{
Nanocrystalline Al Investigated by Transmission Electron Microscope
}

\author{
Marilena $\operatorname{Re}\left({ }^{1}\right)$, Marco Alvisi $\left({ }^{2}\right)$, Ennio Bonetti $\left({ }^{2}\right)$, Leander Tapfer $\left({ }^{1}\right)$ \\ $\left({ }^{1}\right)$ PA.S.T.I.S - C.N.R.S.M.-S.S. 7 Appia km 712, 72100 Brindisi, Italy \\ $\left({ }^{2}\right)$ Dipartimento di Fisica, Università di Bologna e I.N.F.M., via Irnerio 46, 40126 Bologna, Italy \\ (Received March 3; accepted May 9, 1995)
}

\begin{abstract}
Nanocrystalline aluminium ( $\mathrm{n}-\mathrm{Al}$ ), prepared by mechanical attrition in an inert atmosphere and in form of cold consolidated bars, has been investigated by transmission electron microscopy. The effects of three final thinning techniques of preparation for TEM, ion-milling, electrochemical jet-polishing and "powders", have been compared. The most representative samples prove to be those prepared by putting some powder on a carbon film coated grid. Information about the grain sizes for samples prepared by the different techniques and samples before and after a thermal treatment $(500 \mathrm{~K})$ has been obtained. We have also reported our high-resolution images of interfaces.
\end{abstract}

\section{Introduction}

Recently, the experimental studies of the structure and the physical properties of nanostructured materials attract much attention due to their interesting potential technological applications [1,2]. As a matter of fact their novel interesting physical properties are determined by two structural parameters of major concern: the grains whose dimensions are typically $<10^{2} \mathrm{~nm}$ and the interfaces, constituting a relevant volume fraction of the material $[2,3]$.

The main synthesis methods for pure metals and alloys are the "inert gas condensation" technique pioneered by Gleiter [2] and the "mechanical attrition" technique [3-6].

One of the main questions concerns the nature of the interfaces and the existence of a "glass-like phase" at grain boundaries (GB). Measurements by Gleiter [2] and successively by Haubold [7] were interpreted as high disordered interfacial regions. Some subsequent HRTEM observations on different nanostructured materials produced by gas condensation [8-10] seem consistent with the picture that GB in nanostructured materials are similar to those in coarse-grained materials. Some of the authors suggest that the results of such observations must be taken with care due to possible artifacts introduced during the samples preparation for TEM, such as significant structure relaxation. Up to now few works have been reported on TEM observations on nanostructured materials prepared by mechanical attrition (MA) $[3,5,11]$.

In this work we report on some preliminary HRTEM observations on $\mathrm{n}-\mathrm{Al}$ obtained by MA. Particular attention was dedicated to understand how different samples preparation procedures 
for TEM may affect the experimental results in order to obtain representative images of $\mathrm{n}-\mathrm{Al}$ and of interfaces and structural defects.

\section{Experimental}

n-Al was prepared by MA. Pure Al powders (99.99\% purity) were ball milled in a Spex MixerMill, model 8000, using hardened steel balls and a tungsten carbide vial under Ar atmosphere. The ball to powder weight ratio was 4:1. After different milling times, a small quantity of milled powder was removed. $\mathrm{n}-\mathrm{Al}$ was in form of cold consolidated powder bars (1GPa), employed also for mechanical characterization [12].

Several samples were prepared from powders ball-milled for $8 \mathrm{~h}$ and for $32 \mathrm{~h}$, before (ascompacted) and after (treated) a heating run up to $500 \mathrm{~K}(2 \mathrm{~K} / \mathrm{min})$. These two kinds of milled powders are representative of two different steps of the milling process: powders ball-milled for $8 \mathrm{~h}$ are already nanocrystalline but in a non-stable state, while powders ball-milled for $32 \mathrm{~h}$ are in a relatively stable state, when the ultimate grain size is reached.

Discs of about $3 \mathrm{~mm}$ diameter were cut from the bars and, after the first mechanical thinning, subjected to different final thinning procedures as follows:

- the samples ( $\mathrm{Al} 8 \mathrm{~h}$ as-compacted and treated), marked $\mathrm{EJ}$, were prepared by electrochemical jet-polishing with a $30 \% \mathrm{HNO}_{3}$ and $70 \%$ methanol solution kept at $-30^{\circ} \mathrm{C}$ and $20 \mathrm{~V}$ applied;

- the samples ( $\mathrm{Al} 32 \mathrm{~h}$ as-compacted and treated), marked IM, were thinned from both sides simultaneously and constantly rotated (about $2 \mathrm{rev} / \mathrm{min}$ ), using $\mathrm{Ar}^{+}$ion beam at $4 \mathrm{kV}$ at a glancing incidence angle of about $13^{\circ}$ with efficient liquid nitrogen cooling, in order to reduce the increase of the temperature. In the last part of the milling process we used a lower beam energy and current to remove the damaged layers of the sample (ion milled from both sides, rotation of $10 \mathrm{rev} / \mathrm{min}$, $2 \mathrm{kV}$, reduced beam current and the same incident angle);

- the same kinds of samples ( $\mathrm{Al} 8 \mathrm{~h}$ and $\mathrm{Al} 32 \mathrm{~h}$ both as-compacted), marked $\mathrm{P}$, were prepared by transferring a small quantity of powder on a carbon film coated grid. This method avoids the introduction of artificial effects.

All samples were observed by the microscope JEOL 4000 EXII at a voltage of $400 \mathrm{kV}$ (point resolution of $0.166 \mathrm{~nm}$ ). Conventional Bright-field and Dark-field images were taken in order to study the grain size distribution and the effects of the preparation, while high-resolution images, formed by the interference of the transmitted beam and the (111) and (200) diffracted beams, gave an idea of microstructure. Measurements of the grain sizes from Bright-field and Dark-field images were carried out on photographic plates with an eye-piece micrometer and the results were processed using a statistical approach.

\section{Experimental Results}

Many areas of the different samples were examined. In Figure 1 there is a typical diffraction pattern taken from the sample Al $32 \mathrm{~h} \mathrm{IM}$, which shows several rings consisting of spots. The interplanar spacings $d_{h k l}$ corresponding to the rings are those of $\mathrm{Al}$. In the inner part of the first ring an accurate examination of the plate revealed the presence of some spots, which may be attributed to $\mathrm{Al}_{2} \mathrm{O}_{3}$. These features appear for all samples prepared with the different techniques.

Figure 2a shows a Bright-field micrograph of the sample $\mathrm{Al} 32 \mathrm{~h}$ IM: grains with a dark contrast dispersed in a matrix with a different contrast are evident. The sudden change of thickness among neighbouring areas causes a variation of the contrast in the matrix. Figure $2 \mathrm{~b}$ shows a high-resolution image of the same specimen, where there are areas in the zone axis $<110>$, areas with unidimensional fringes and areas with an attenuation of the contrast. 


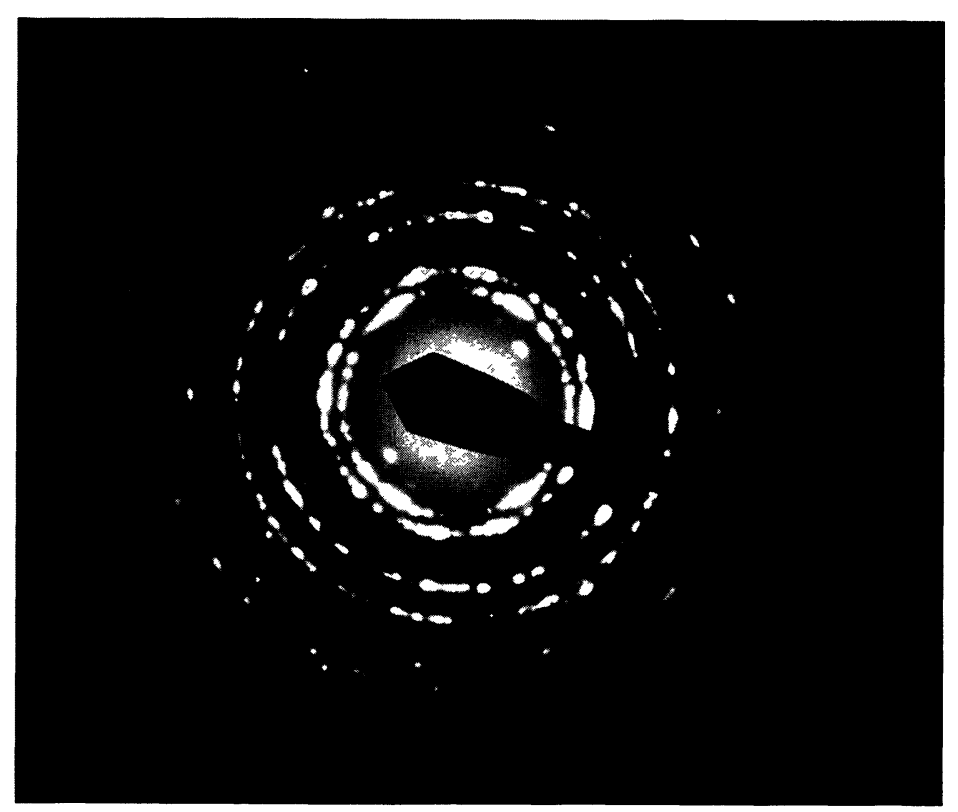

Fig. 1. - Typical diffraction pattern of sample $\mathrm{Al} 32 \mathrm{~h} \mathrm{IM}$.

A Bright-field micrograph of the sample $\mathrm{Al} 8 \mathrm{~h}$ EJ is reported in Figure 3a: grains, sometimes overlapped, are dispersed in a matrix with an evident roughness. The difference in thickness among neighbouring areas should cause the variation of contrast in the high-resolution image (Fig. 3b) of the same sample.

In high-resolution images taken from samples prepared both with ion-milling and electrochemical jet-polishing techniques, it is difficult to distinguish single grains and areas not in the right orientation appear.

It should be noted the remarkable difficulty to prepare samples suitable for HRTEM observations. In fact, the surfaces after the final thinning both with ion-milling and electrochemical jet-polishing, showed an evident roughness and a non-uniform thickness, perhaps because the material consists of ball-milled powders in form of consolidated bars.

Figures $4 \mathrm{a}$ and $4 \mathrm{~b}$ show the Bright-field image and the high-resolution image of the sample $\mathrm{Al}$ $32 \mathrm{~h} \mathrm{P}$, respectively. In this case the grains appear not so dispersed as in the previous cases: there are many areas with Moirè fringes, because of the overlapping of the grains and it is easier to distinguish each grain in high-resolution images.

Since it was difficult to individuate every grain in Bright-field images also because of their overlapping, we obtained Dark-field images formed by selecting different portions of the (111) and (200) rings in the diffraction pattern. Even if the Dark-field images allow us to individuate the grains better, in some cases it was impossible to discriminate between two grains partially overlapped.

The grain size distributions are reported in Figure 5 for samples ball-milled for $8 \mathrm{~h}$ and in Figure 6 for samples ball-milled for $32 \mathrm{~h}$. By comparing the experimental size distributions of samples $P$ with samples $32 \mathrm{~h}$ thinned by ion milling it can be observed an increase of the grain sizes, which could mask a real effect of the thermal treatment; for samples $8 \mathrm{~h}$ thinned by electrochemical jet-polishing there is no such increase, while the thermal treatment has caused an evident change in the grain sizes. 


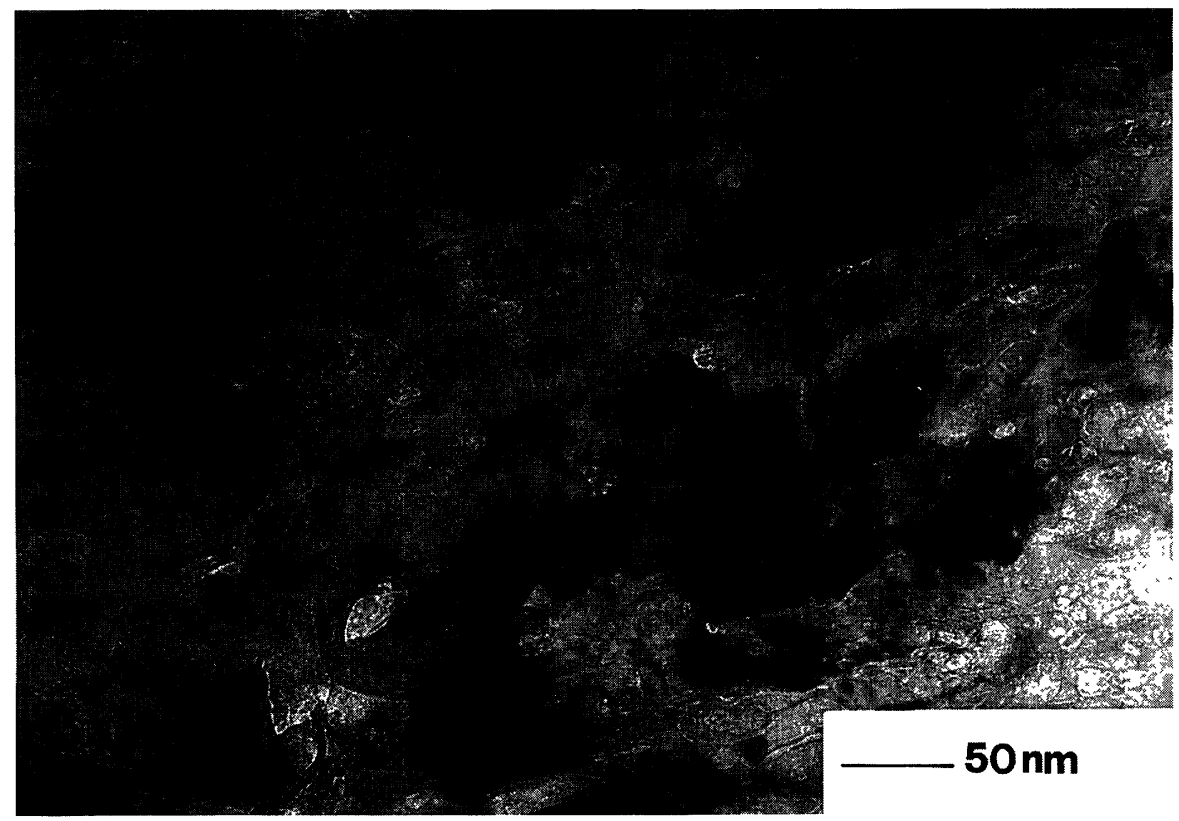

a)

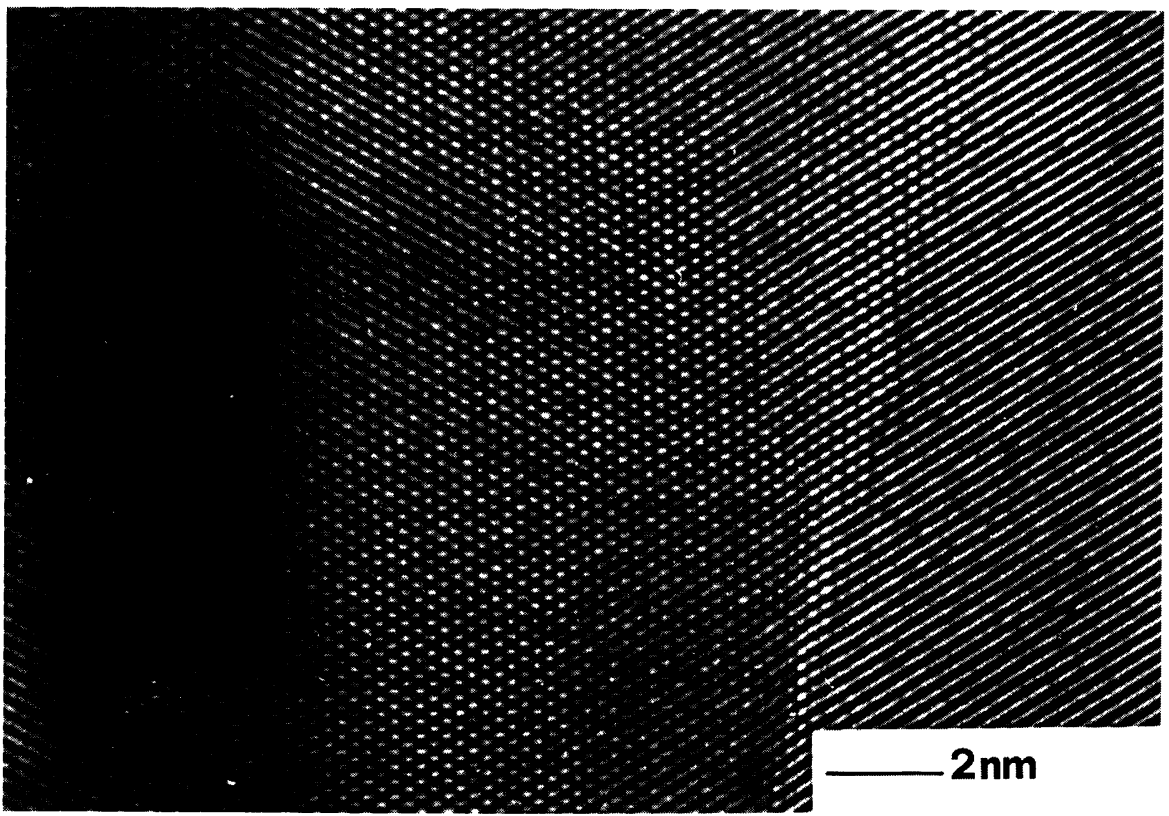

b)

Fig. 2. - a) Bright-field image of sample $\mathrm{Al} 32 \mathrm{~h} \mathrm{IM}$ (thinned by ion milling); b) high-resolution image of the same sample. 


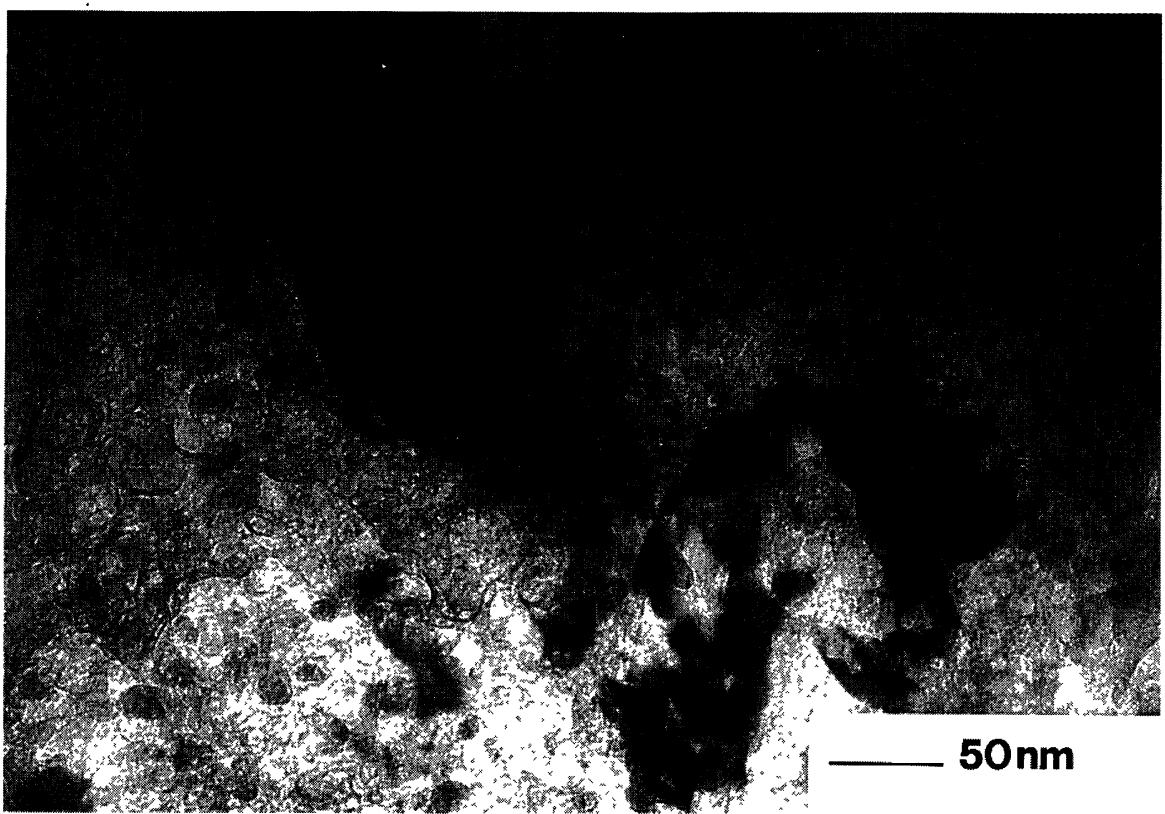

a)

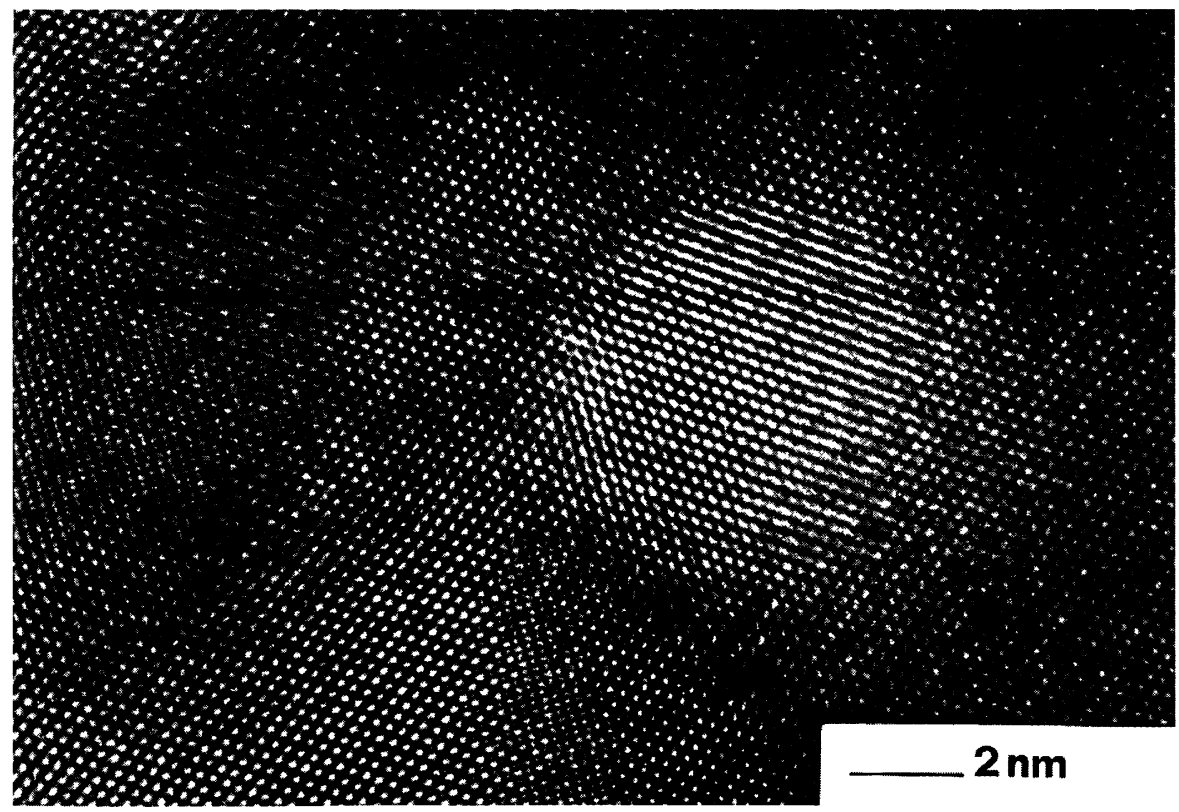

b)

Fig. 3. - a) Bright-field image of sample $\mathrm{Al} 8 \mathrm{~h} \mathrm{EJ}$ (thinned by electrochemical jet-polishing); b) highresolution image of the same sample. 


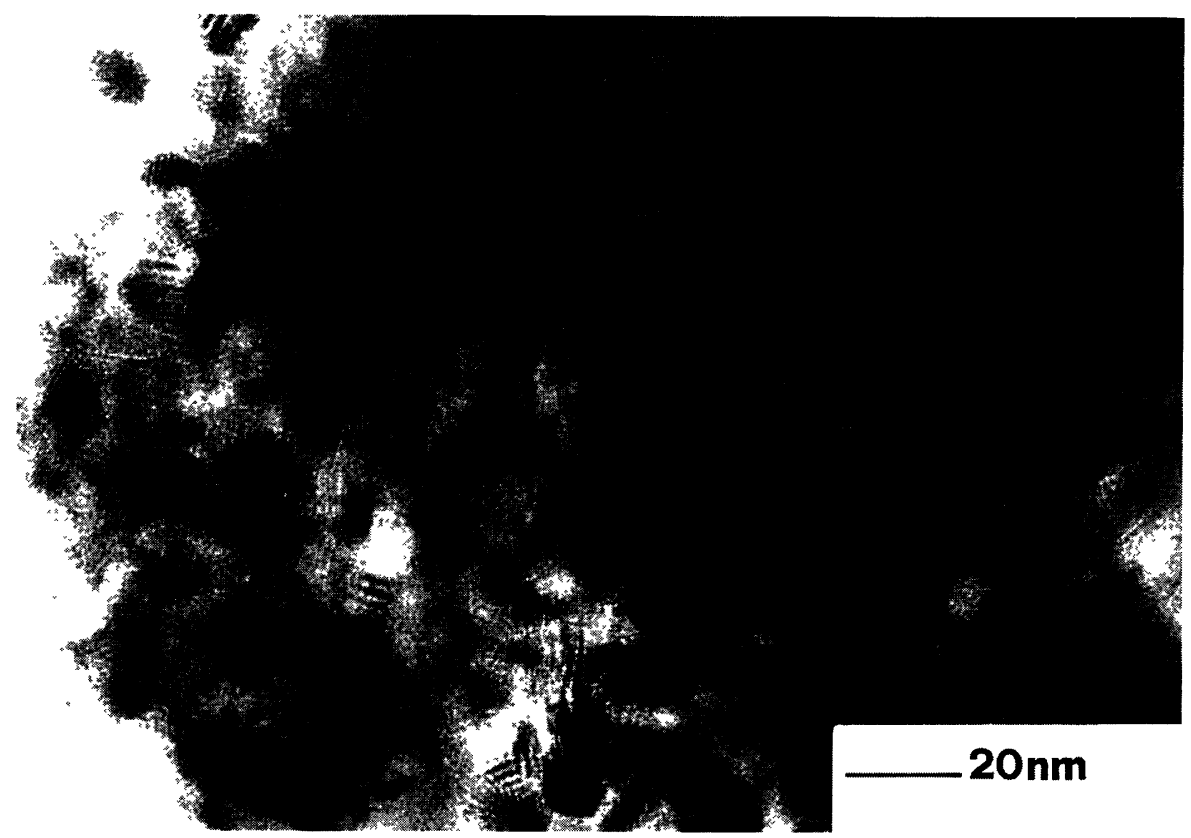

a)

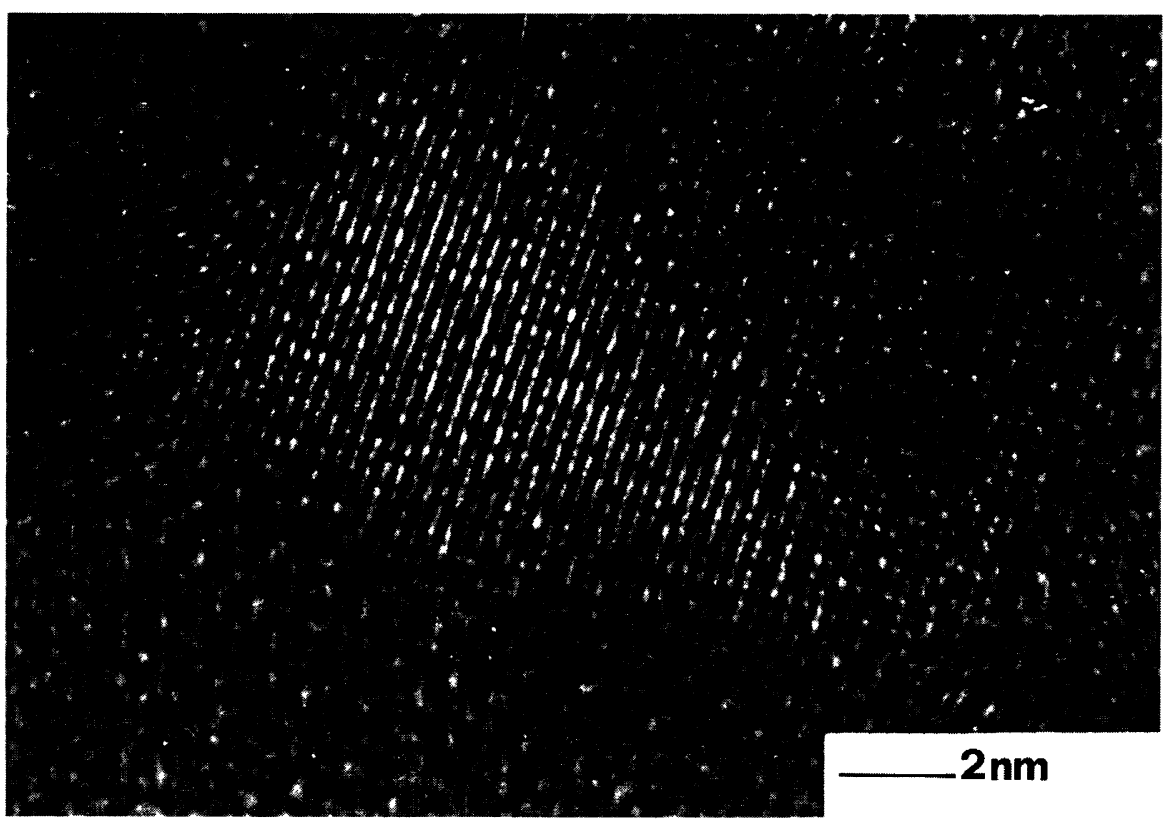

b)

Fig. 4. - a) Bright-field image of sample $\mathrm{Al} 32 \mathrm{~h} \mathrm{P}$ (powders on a carbon film coated grid); b) highresolution image of the same sample. 

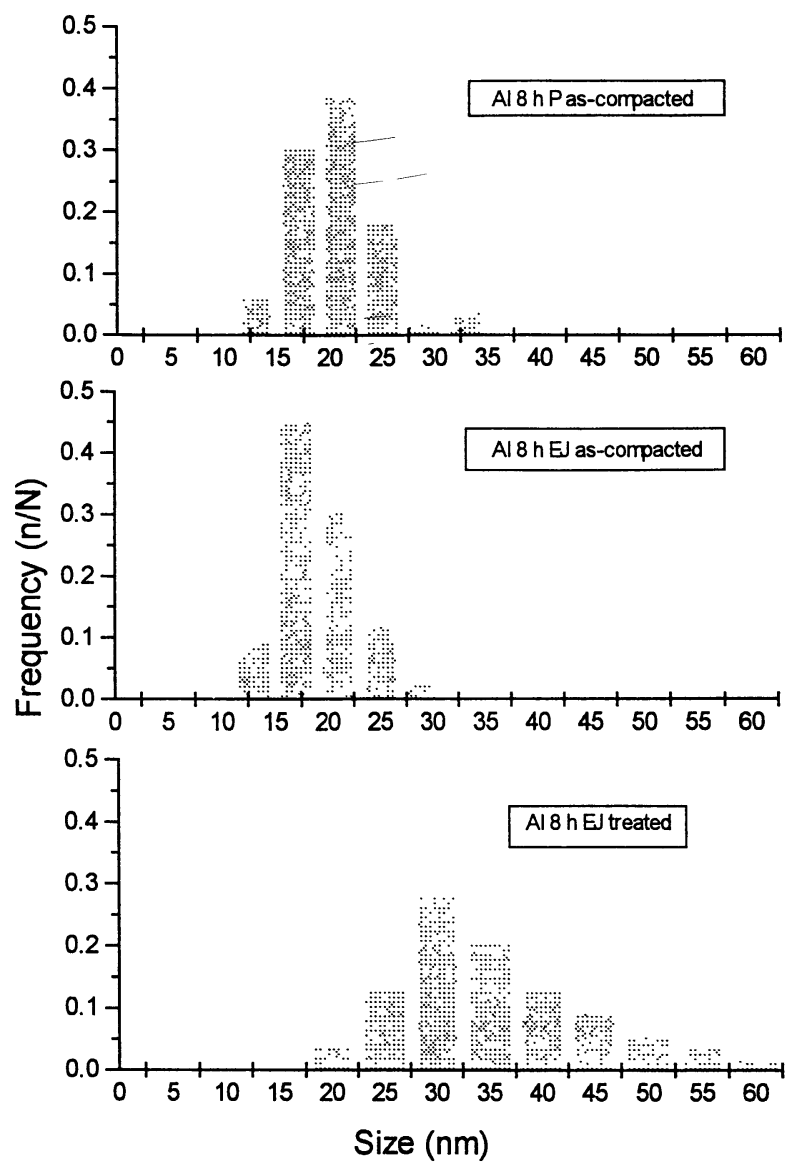

Fig. 5. - Histograms of the grain size distributions obtained for samples Al ball-milled for $8 \mathrm{~h}$ P (ascompacted), EJ (as-compacted) and EJ (treated).

Figure 7 shows a high-resolution image of an area of the sample $\mathrm{Al} 8 \mathrm{~h} \mathrm{EJ}$ as-compacted, where some structural defects in the grain can be observed. They might be stacking-faults or microtwins. We did not observe the same features in the samples ball-milled for $32 \mathrm{~h}$.

Since the main aim is the study of local structure in $\mathrm{n}-\mathrm{Al}$, we tried to take high-resolution images of interfaces. For a quantitative interpretation of HRTEM images of interfaces, the boundary should be of pure tilt and oriented parallel to the electron beam, but the small grain sizes prevent from orienting the samples in the right way. In our first high-resolution images taken from the samples $\mathrm{Al} 32 \mathrm{~h}$ IM treated and $\mathrm{Al} 32 \mathrm{~h} \mathrm{P}$ as-compacted, Figures 8 and 9 (respectively), it is possible to individuate the interface in some areas.

Figure 8 shows two sets of lattice fringes (111) of two neighbouring grains (A and B) in a different orientation, but the interface is not so evident, perhaps because it might be not perfectly aligned parallel to the electron beam. In Figure 9, in spite of a low contrast, some interfaces are more distinguishable. The estimated grain size agrees with those obtained from Dark-field images for the same sample. 

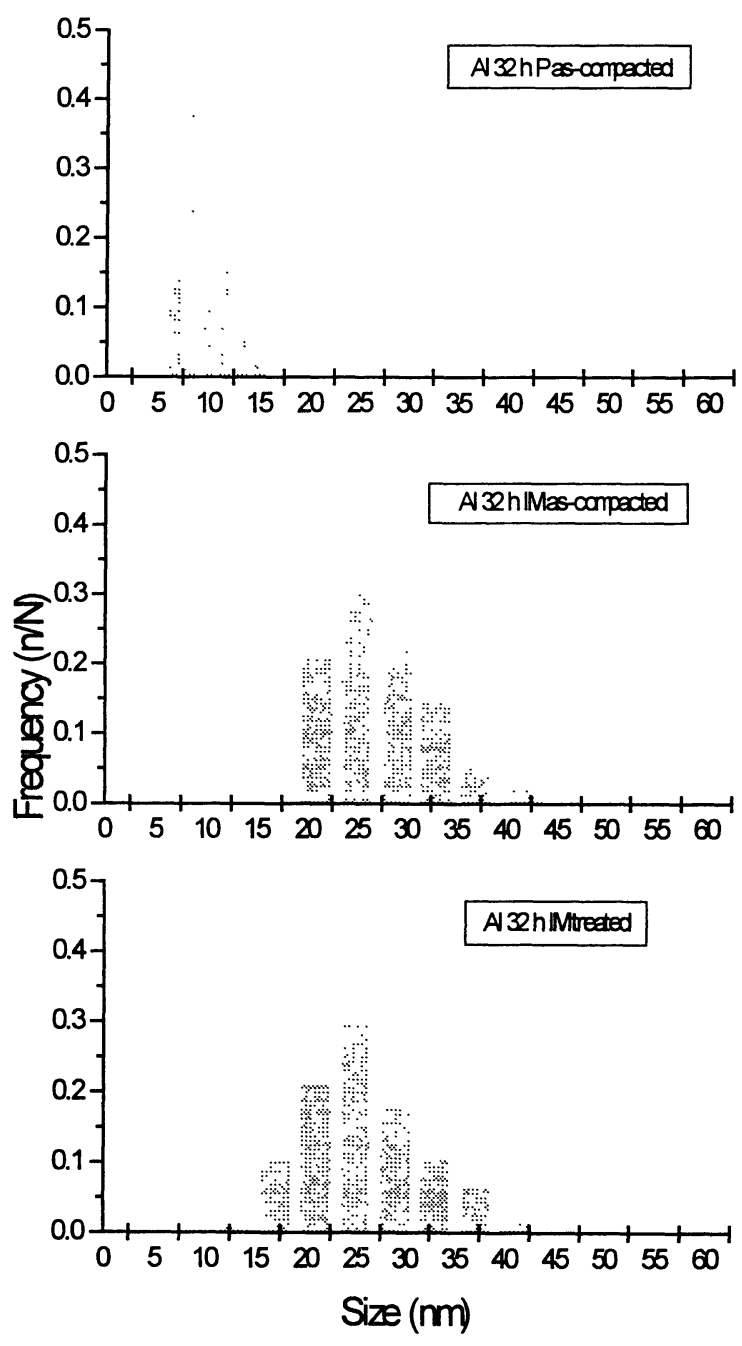

Fig. 6. - Histograms of the grain size distributions obtained for samples Al ball-milled for $32 \mathrm{~h}$ P (ascompacted), IM (as-compacted) and IM (treated).

\section{Discussion and Conclusion}

Our experimental results have shown that it is impossible to neglect the effect of ion-milling process and electrochemical jet-polishing on the samples of n-Al. In fact the grains appear as dispersed in a matrix with a different contrast and their sizes might be influenced. On the contrary samples prepared by transferring the milled powders on a carbon film coated grid are more representative of the structure of $\mathrm{n}-\mathrm{Al}$ : the crystalline areas are prevalent on the amorphous substrate and it is easier to distinguish each grain. The only difficulty of this method is that there are not many areas with thickness suitable for high-resolution images of a very good quality and in many cases the smaller powder particles can be not well representative of the grain size distribution of the whole material. 


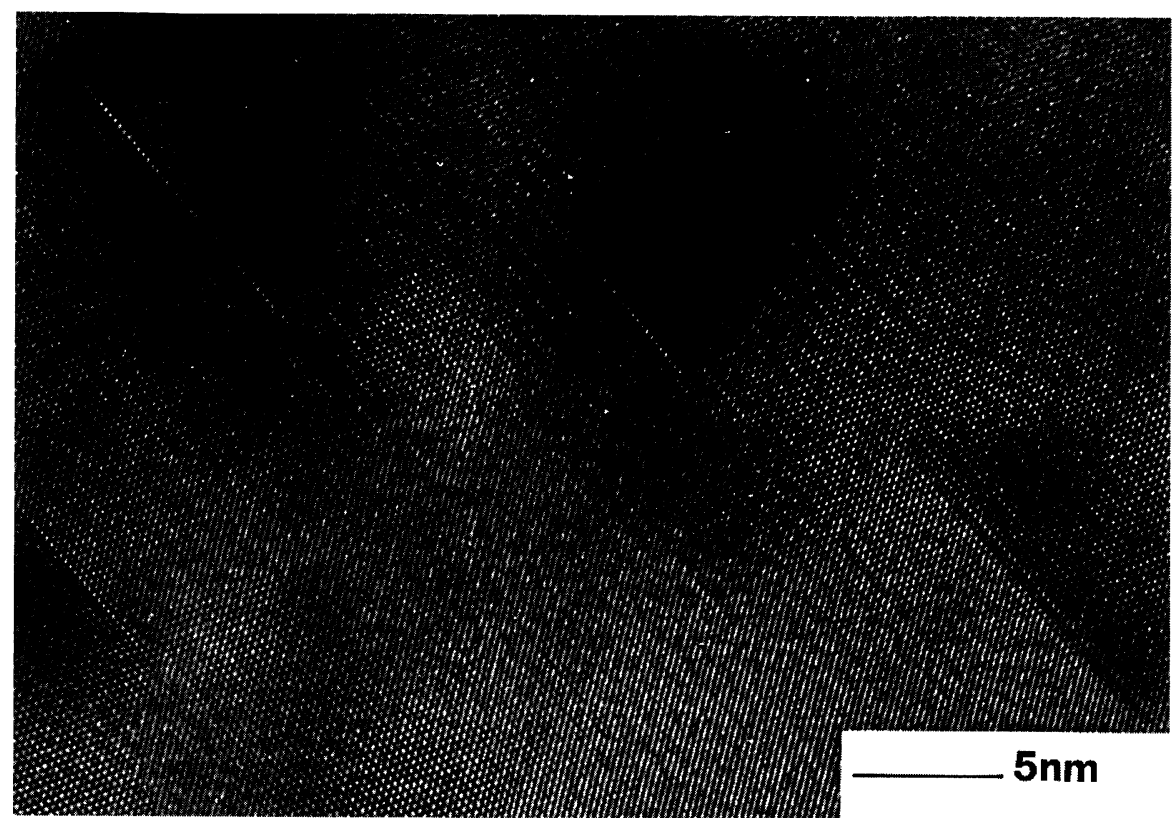

Fig. 7. - High-resolution image of an area of a sample Al $8 \mathrm{~h} \mathrm{EJ} \mathrm{(as-compacted)} \mathrm{with} \mathrm{some} \mathrm{structural}$ defects.

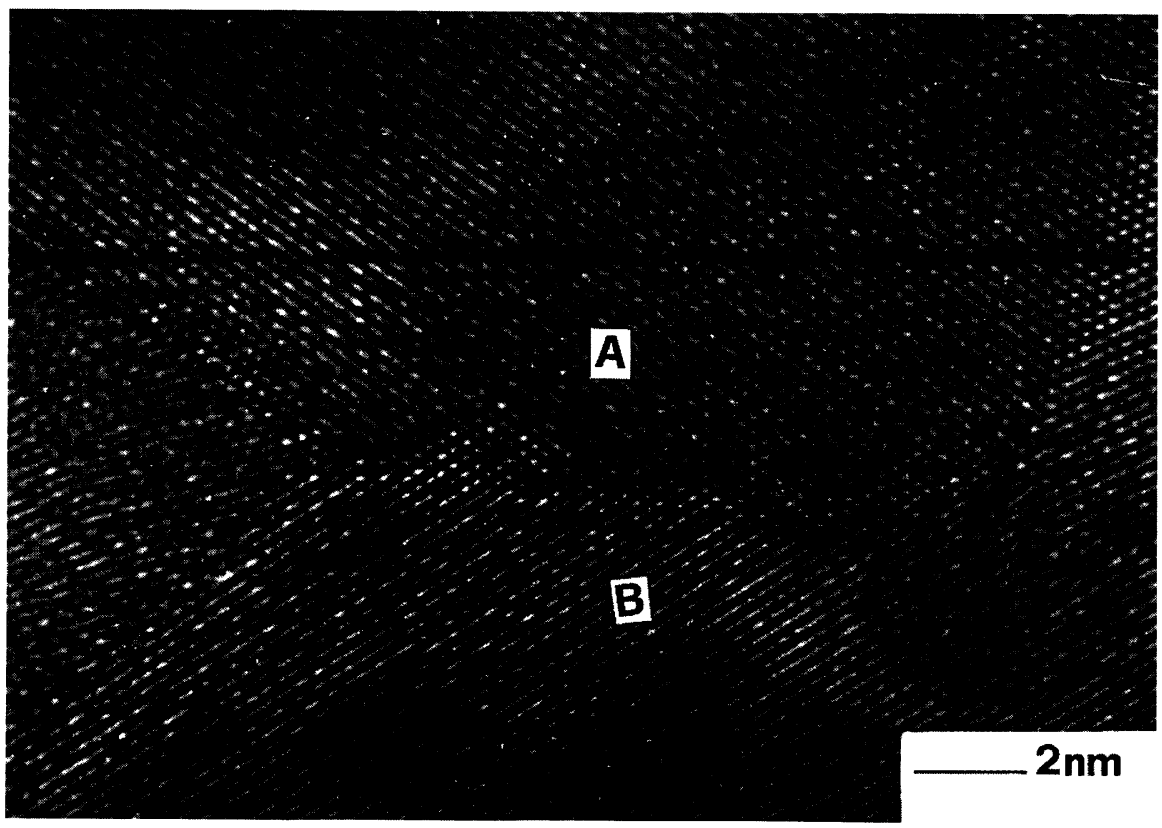

Fig. 8. - High-resolution image of a sample $\mathrm{Al} 32 \mathrm{~h} \mathrm{IM}$ (as-compacted), where the lattice fringes of two neighbouring grains are disoriented. 


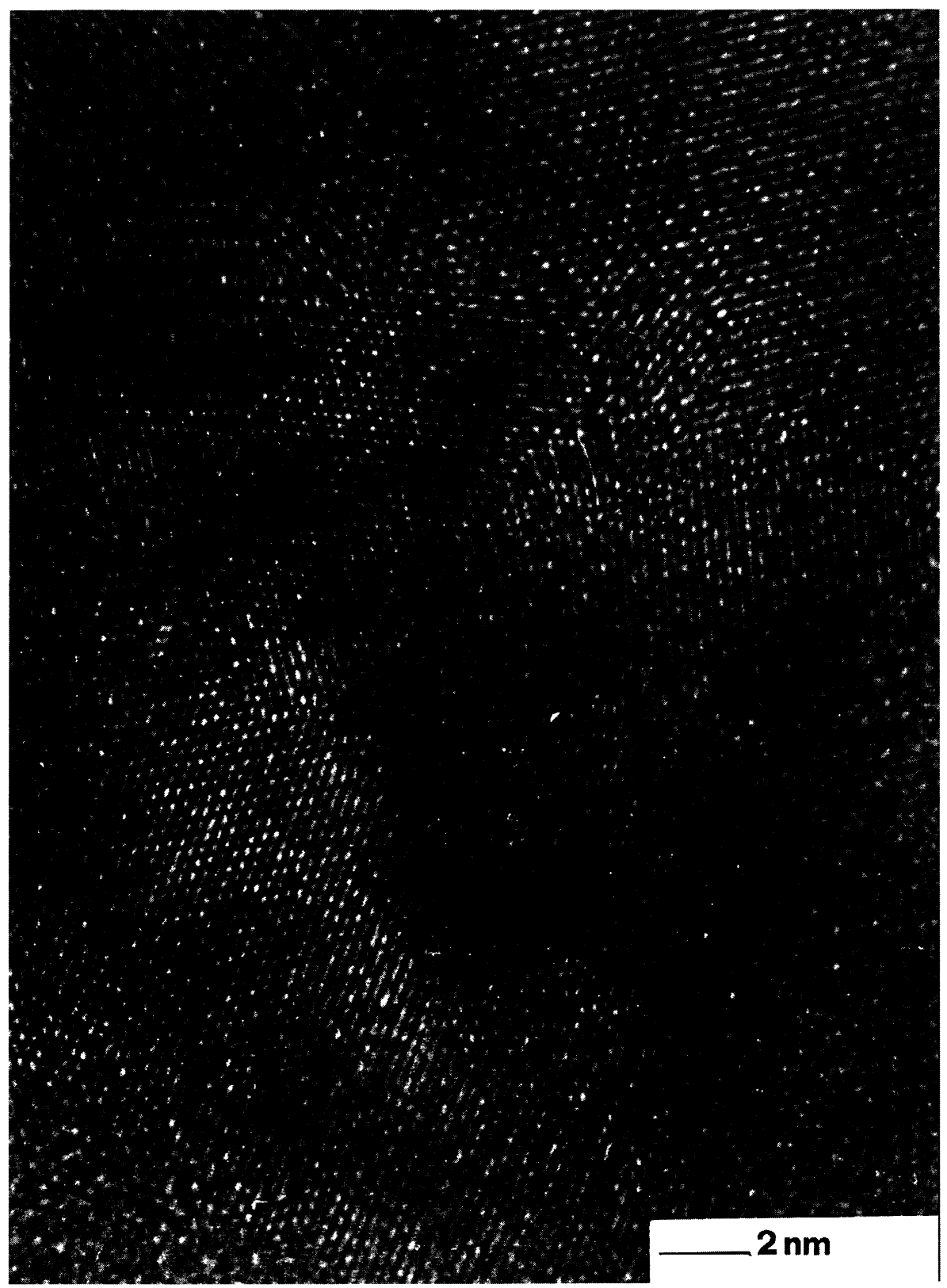

Fig. 9. - High-resolution image of a sample $\mathrm{Al} 32 \mathrm{~h} \mathrm{P}$ (as-compacted) with some interfaces.

Considering these facts, now we can analyse the grain size distributions reported in Figures 5 and 6.

- In samples $8 \mathrm{~h} \mathrm{P}$ and EJ there is not a remarkable effect on the grain sizes due to the final preparation.

- In samples $8 \mathrm{~h}$ EJ as-compacted and treated a significant increase of the average grain size 
is observed: the distribution is quite larger. After a time of $8 \mathrm{~h}$ the ball-milled powders are in a non-stable state and there is a growth of the larger grains to the detriment of the smaller ones.

- For samples ball-milled for $32 \mathrm{~h} \mathrm{P}$ and IM it seems that the ion-milling, even if with the efficient liquid nitrogen cooling, has caused an increase of the grain sizes. In fact in this step of the ball milling process the grains have reached their ultimate size, so they are more sensitive to the final thinning effects. Because of these possible undesirable effects it is difficult to draw a definitive conclusion about the influence of the thermal treatment on the grain size.

The observed structural defects in samples ball-milled for $8 \mathrm{~h}$ might be caused by the electron beam, but we did not observe the same feature for samples ball-milled for $32 \mathrm{~h}$. If these structural defects are typical of the material after a $8 \mathrm{~h}$ ball-milling, this finding should agree with Fecht's description of the microstructural evolution and grain refinement during the ball-milling process $[3,13]$ : in the early stage of MA a high density of defects and a larger strain are present, while the strain and the defects density drop when the grain size reaches the ultimate value.

Even if our first high-resolution images are not of satisfactory quality because of the great difficulty to obtain samples of the right thickness, it is possible to individuate the interfaces in some areas: no amorphous layer seems to be at the interfaces, but it is very difficult to evaluate the interface widths and disorder. Further examinations on powder samples are necessary to achieve definitive results about the microstructure of the interfaces at different milling times and also after a thermal treatment in order to study the correlation between microstructure and mechanical properties of $\mathrm{n}-\mathrm{Al}$.

\section{Acknowledgements}

The authors are grateful to G. Cocco and his co-workers, Università di Sassari, for supplying the ball-milled aluminium and for useful discussion, and to M. Palmisano, PA.S.T.I.S.-C.N.R.S.M., for the technical assistance.

\section{References}

[1] Siegel R.W., Nanostruct. Mater. 3 (1993) 1.

[2] Gleiter H., J. Appl. Cryst. 24 (1991) 79.

[3] Eckert J., Holzer J.C., Krill C.E., Johnson W.L., J. Mater Res. 7 (1992) 1751.

[4] Koch C.C. and Cho Y.S., Nanostruct. Mater. 1 (1992) 207.

[5] Fu Z., Johnson W.L., Nanostruct. Mater. 3 (1993) 175.

[6] Gao Z., Fultz B., Nanostruct. Mater. 2 (1993) 231.

[7] Haubold T., Birringer R., Lenger B., Gleiter H., Phys. Lett. A 135 (1989) 461.

[8] Thomas G.J., Siegel R.W. and Eastmann J.A., Script. Metall. Mater. 24 (1990) 201.

[9] Li D.X., Ping D.H., Ye H.Q., ICEM 13-Paris (July 1994) (Editions de Physique, Les Ulis, France, 1994) p. 361.

[10] Kizuka et al., Philos. Mag. A 69 (1994) 551.

[11] Trudeau M.L. and Schulz R., Mat. Sci. Ing. A 134 (1991) 1361.

[12] Bonetti E., Valdrè G., Philos. Mag. B 68 (1993) 967.

[13] Hellstern E., Fecht H.J., Fu Z., Johnson W.L., J. Appl. Phys. 65 (1989) 305. 